Article

\title{
Suppression of Rice Cryptochrome 1b Decreases Both Melatonin and Expression of Brassinosteroid Biosynthetic Genes Resulting in Salt Tolerance
}

\author{
Ok Jin Hwang and Kyoungwhan Back * (1)
}

Bioenergy Research Center, Department of Biotechnology, College of Agriculture and Life Sciences, Chonnam National University, Gwangju 61186, Korea; smilax@jnu.ac.kr

* Correspondence: kback@chonnam.ac.kr; Tel.: +82-62-530-2165

Citation: Hwang, O.J.; Back, K. Suppression of Rice Cryptochrome $1 \mathrm{~b}$ Decreases Both Melatonin and Expression of Brassinosteroid Biosynthetic Genes Resulting in Salt Tolerance. Molecules 2021, 26, 1075. https://doi.org/10.3390/

molecules 26041075

Academic Editor: Claus Jacob

Received: 3 February 2021

Accepted: 17 February 2021

Published: 18 February 2021

Publisher's Note: MDPI stays neutral with regard to jurisdictional claims in published maps and institutional affiliations.

Copyright: (c) 2021 by the authors. Licensee MDPI, Basel, Switzerland. This article is an open access article distributed under the terms and conditions of the Creative Commons Attribution (CC BY) license (https:// creativecommons.org/licenses/by/ $4.0 /)$.

\begin{abstract}
We investigated the relationship between the blue-light photoreceptor cryptochrome (CRY) and melatonin biosynthesis by generating RNA interference (RNAi) transgenic rice plants that suppress the cryptochrome $1 b$ gene $(C R Y 1 b)$. The resulting $C R Y 1 b$ RNAi rice lines expressed less CRY1b mRNA, but not CRY1a or CRY2 mRNA, suggesting that the suppression is specific to CRY1b. The growth of $C R Y 1 b$ RNAi rice seedlings was enhanced under blue light compared to wild-type growth, providing phenotypic evidence for impaired CRY function. When these CRY1b RNAi rice plants were challenged with cadmium to induce melatonin, wild-type plants produced $100 \mathrm{ng} / \mathrm{g}$ fresh weight (FW) melatonin, whereas CRY1b RNAi lines produced $60 \mathrm{ng} / \mathrm{g}$ FW melatonin on average, indicating that melatonin biosynthesis requires the CRY photoreceptor. Due to possible feedback regulation, the expression of melatonin biosynthesis genes such as T5H, SNAT1, SNAT2, and COMT was elevated in the $C R Y 1 b$ RNAi lines compared to the wild-type plants. In addition, laminar angles decreased in the CRY1b RNAi lines via the suppression of brassinosteroid (BR) biosynthesis genes such as $D W A R F$. The main cause of the BR decrease in the CRY $1 b$ RNAi lines seems to be the suppression of CRY rather than decreased melatonin because the melatonin decrease suppressed DWARF4 rather than DWARF.
\end{abstract}

Keywords: cadmium; blue-light photoreceptors; brassinosteroids; CRY1b; melatonin; transgenic rice

\section{Introduction}

Light-dependent melatonin synthesis occurs in some plant species, whereas in other plants, melatonin exhibits a nocturnal increase similar to that in animals [1-4]. Melatonin is broadly implicated in many physiological activities in plants, where it mostly serves as a potent free radical scavenger, signal molecule, or hormone via the mitogen-activated protein kinase (MAPK) signaling pathway [5-9]. Although a plant melatonin receptor was recently reported [10], its integrity remains controversial and requires further study [11]. The major known functions of melatonin are plant defense responses against both biotic and abiotic stresses [12,13], plant growth, and reproduction [7,14]. Briefly, melatonin is closely involved in conferring tolerance against endoplasmic reticulum stress $[15,16]$, salt $[17,18]$, pathogens [19,20], high temperatures [21,22], high light stress [23], and other stresses [24]. Melatonin also plays roles in plant growth and reproduction, including the synthesis of secondary metabolites [25,26], germination [27], seed longevity [28], hormone synthesis [29,30], fruit yield [31], and other processes [32].

The melatonin biosynthesis pathways have been well-characterized with the successful cloning of relevant biosynthesis genes [8]. It is clear that melatonin induction is dependent on light based on experiments in which rice plants were challenged with cadmium, which is the best inducer of melatonin [2]. The pivotal gene responsible for melatonin induction under light is that encoding tryptophan decarboxylase (TDC), the first committed step enzyme in melatonin biosynthesis, which converts tryptophan into 
tryptamine. The optimal light for the maximum induction of melatonin was found to be a combination of red and blue light, rather than red or blue alone; far-red light is unable to induce melatonin in response to cadmium treatment in rice, indicating that melatonin synthesis is predominantly associated with photosynthesis rather than with other photoreceptors such as phytochromes [33].

Light is indispensable for plant growth via photosynthesis, during which mainly red $(720 \mathrm{~nm})$ and blue $(450 \mathrm{~nm})$ wavelengths are absorbed via photosynthetic pigments, including chlorophyll [34]. Light is also an important signal that influences plant life and death from germination to reproduction. Plants have evolved specific photoreceptors that respond to different light wavelengths. For instance, phytochromes absorb red $(600-700 \mathrm{~nm})$ and far-red $(700-750 \mathrm{~nm})$ light as part of their biological functions, whereas phototropins and cryptochromes (CRY) sense ultraviolet A/blue light $(390-500 \mathrm{~nm})$. The first molecular genetic analysis of the possible involvement of photoreceptors in melatonin synthesis was recently reported, in which rice phytochrome mutants exhibited decreased melatonin synthesis compared to wild-type plants, confirming a previous report that melatonin synthesis requires light [33]. However, the possible involvement of CRY in melatonin biosynthesis in plants remains unclear [35]. Here, we generated transgenic rice plants that suppressed rice $C R Y 1 b$ to investigate if $C R Y$ are also involved in melatonin synthesis in rice. The rice genome contains a small CRY gene family that includes CRY1a (AB024337), CRY1b (AB098568), and CRY2 (AK065669). CRY1a exhibits greater homology with CRY1b (75\% identity), whereas CRY1a and CRY1b exhibit less homology with CRY2, with amino-acid sequence identities of $46 \%$ and $47 \%$, respectively [36]. Of the three $C R Y$ genes, $C R Y 1 b$ was reported to be associated with blue light-dependent phenotypes in Arabidopsis and rice [37]. Therefore, we chose rice $C R Y 1 b$ to develop transgenic RNAi rice plants to examine whether CRY is involved in melatonin biosynthesis (Figure 1a). Due to the high homology between CRY1a and CRY1b, we selected a C-terminal portion of $C R Y 1 b$ that exhibits greater sequence diversity from that in $C R Y 1 a$ for RNA silencing.

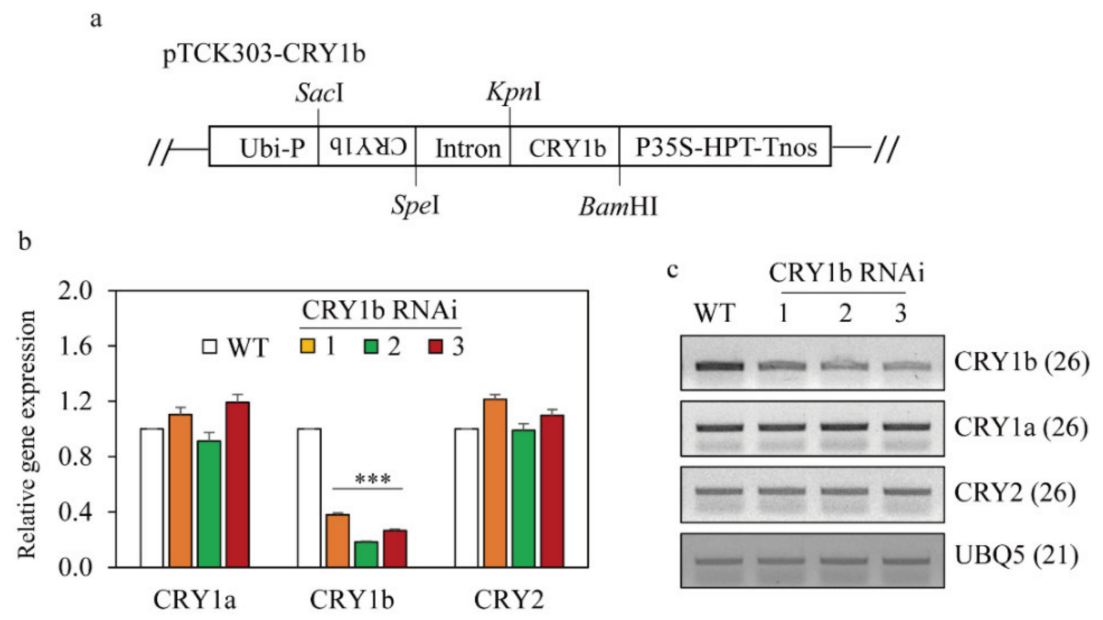

Figure 1. The structure of binary vector PTCK303 and the generation of $C R Y 1 b$-suppressed transgenic rice plants. (a) Schematic diagram of the pTCK303:CRY1b binary vector. (b) Results of quantitative real-time polymerase chain reaction (PCR) analyses. (c) Results of reverse transcription-PCR analyses of the wild-type and transgenic (T2) lines. Rice seeds were germinated in half-strength Murashige and Skoog (MS) medium and grown for 8 days at $28^{\circ} \mathrm{C}$ under a 14-h light/10-h dark cycle. Total RNA was extracted from these seedlings. CRY1b, Oryza sativa cryptochrome $1 b$; Ubi-P, maize ubiquitin promoter; HPT, gene encoding hygromycin phosphotransferase. Asterisks $\left(^{* * *}\right)$ indicate significant differences from the wild type $(p<0.001)$. GenBank accession numbers are AB024337 $(C R Y 1 a)$, AB098568 (CRY1b), AK065669 (CRY2), and Os03g13170 (UBQ5). Numbers in parentheses indicate the numbers of PCR cycles. 


\section{Results and Discussion}

\subsection{Generation of Transgenic Rice Plants Suppressing Rice CRY1b}

From four independent T1 lines, we selected three homozygous T2 transgenic lines (Figure $1 \mathrm{~b}, \mathrm{c}$ ). CRY1b was significantly suppressed in the three CRY1b RNAi lines, whereas $C R Y 1 a$ and $C R Y 2$ mRNA levels were comparable to those in the wild type according to qRT-PCR and semiquantitative RT-PCR analyses. These data indicated the successful, specific suppression of $C R Y 1 b$ using RNAi. The lengths and second leaf sheath lengths of 8-day-old wild-type and CRY1b RNAi seedlings grown in half-strength Murashige and Skoog (MS) medium under a 12-h light/12-h dark regime with cool fluorescent light were similar (Figure 2a-c). However, seedling length was longer in the CRY1b RNAi lines than in the wild type when seedlings were grown under blue light, as was the length of the second leaf sheath (Figure 2d-f). Notably, wild-type seedling length decreased under blue light versus cool fluorescent light because blue light inhibits seedling growth in monocots, including rice [37,38]. Consistent with this, our transgenic CRY1b RNAi seedlings exhibited significantly reduced inhibition of seedling growth and second leaf sheath length, confirming that our CRY1b RNAi rice plants had a functional defect in the blue-light photoreceptor (CRY). In contrast to results obtained for CRY1b RNAi, the overexpression of $C R Y 1 b$ induced an increased responsiveness to blue light, resulting in severe seedling growth inhibition compared to the wild type [36,37].
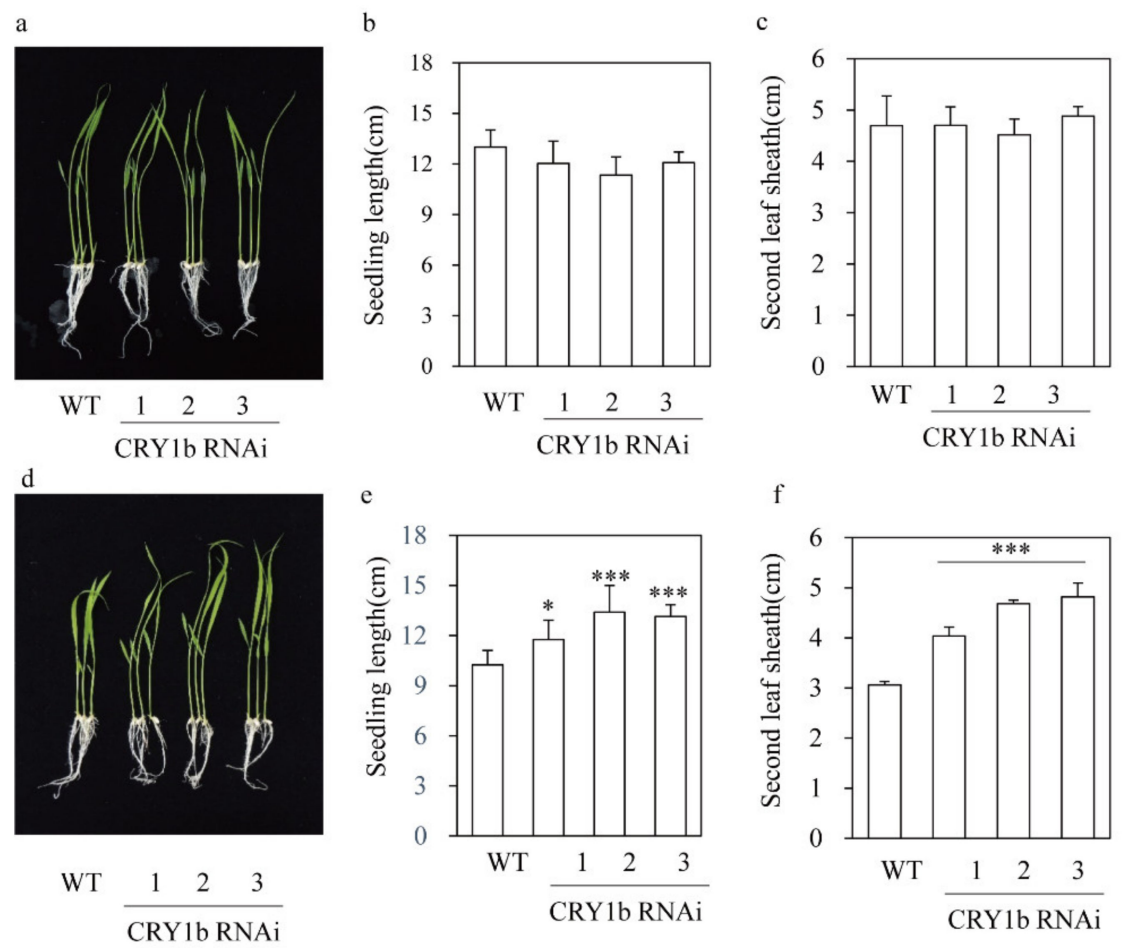

Figure 2. Seedling phenotypes of wild-type (WT) and CRY1b RNAi transgenic rice. (a) Representative seedling phenotypes, (b) shoot lengths, and (c) second leaf sheath lengths of plants grown under cool fluorescent light. (d) Representative seedling phenotypes, (e) shoot lengths, and (f) second leaf sheath lengths of plants grown under blue light. Rice seeds were germinated in half-strength MS medium and grown for 8 days at $28^{\circ} \mathrm{C}$ under a 14-h light/10-h dark cycle. Asterisks denote significant differences $\left({ }^{*} p<0.05, * * * p 0.001\right)$ as determined by Tukey's HSD post-hoc tests. Lines 1-3 are RNAi rice plants with downregulated $C R Y 1 b$ genes.

\subsection{Melatonin Levels in CRY1b RNAi Rice Seedlings}

To determine whether the blue-light photoreceptor (CRY) was associated with melatonin biosynthesis, 8-day-old rice seedlings were challenged with cadmium to induce melatonin. As shown in Figure 3, melatonin levels decreased two-fold in CRY1b RNAi rice 
lines 2 and 3 and by $20 \%$ in line 1 compared to those in the wild type (Figure 3c). A drastic decrease in $N$-acetylserotonin (NAS) levels was observed in all CRY1b RNAi lines, with NAS contents 10-fold less in RNAi lines (166 ng/g fresh weight (FW)) than in the wild type (1750 ng/g FW) (Figure 3b). Conversely, serotonin levels in the CRY1b RNAi lines were indistinguishable from those in the wild type (Figure 3a). These data indicate that the blue-light photoreceptor is involved in melatonin biosynthesis when rice seedlings are challenged with cadmium. Next, we measured the expression of melatonin biosynthesis gene mRNA in 7-day-old rice seedlings in the absence of cadmium. TDC is the first enzyme to participate in melatonin biosynthesis, followed by tryptamine 5-hydroxylase (T5H), which synthesizes serotonin from tryptamine. Serotonin is then acetylated into NAS by serotonin $N$-acetyltransferase (SNAT), which has two isogenes in the rice genome-SNAT1 and SNAT2. The last enzyme in melatonin synthesis is NAS O-methyltransferase (ASMT), which catalyzes the conversion of NAS into melatonin. The caffeic acid $O$-methyltransferase (COMT) exhibiting ASMT enzyme activity plays pivotal roles in melatonin synthesis in rice [39]. The expression of the melatonin biosynthesis genes T5H, SNAT1, SNAT2, and COMT was all elevated in the CRY1b RNAi lines, whereas that of TDC1 was not (Figure 4). The high levels of melatonin biosynthesis gene expression in the CRY1b RNAi lines suggest that feedback regulation compensates for low melatonin levels.
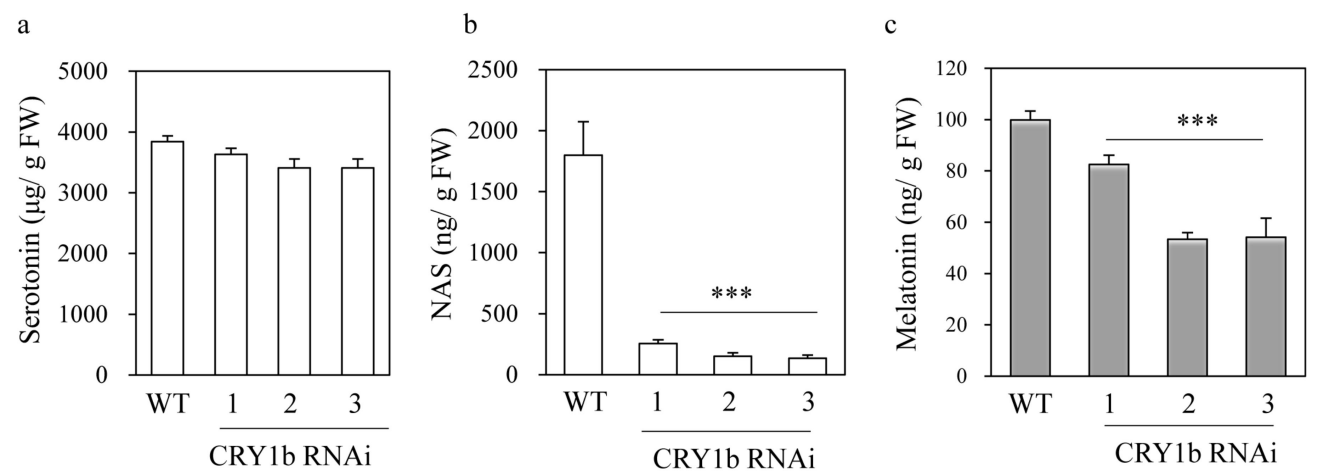

Figure 3. Serotonin, $N$-acetylserotonin, and melatonin contents in WT and CRY1b RNAi lines. (a) Serotonin, (b) Nacetylserotonin (NAS), and (c) melatonin levels in response to cadmium treatment under cool fluorescent light. Eight-dayold rice seedlings were challenged rhizosperically with $0.5 \mathrm{mM} \mathrm{CdCl}_{2}$ for 3 days under cool fluorescent light at a rate of $60 \mu \mathrm{mol} \mathrm{m}{ }^{-2} \mathrm{~s}^{-1}$. Values are presented as the means \pm standard deviations (SDs) of three independent experiments. FW, fresh weight. ${ }^{* *} p<0.001$, Tukey's HSD post-hoc test.

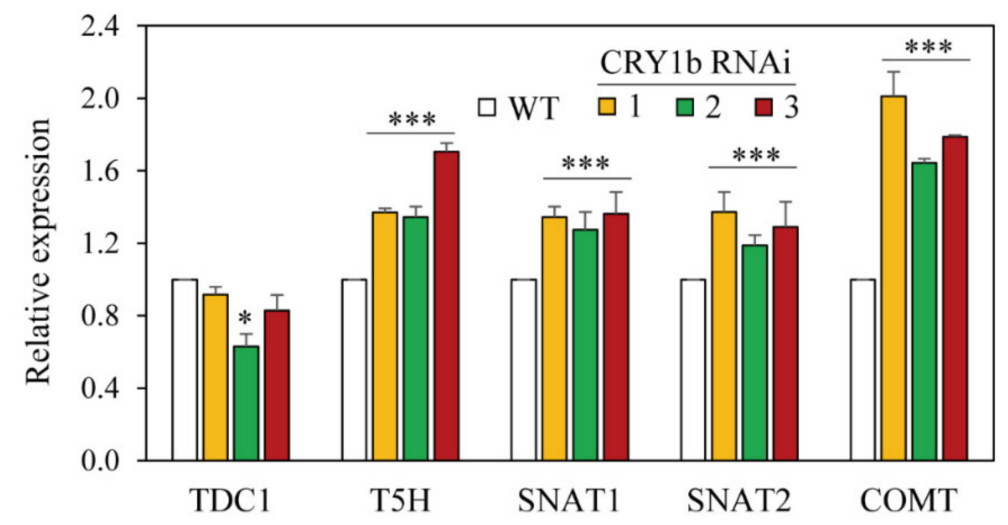

Figure 4. Quantitative real-time PCR analyses of melatonin biosynthesis genes. TDC1, tryptophan decarboxylase 1; T5H, tryptamine 5-hydroxylase; SNAT1, serotonin $N$-acetyltransferase 1; SNAT2, serotonin $\mathrm{N}$-acetyltransferase 2; COMT, caffeic acid $O$-methyltransferase. ${ }^{*} p<0.05$ and ${ }^{* * *} p<0.001$ vs. the WT. GenBank accession numbers are AK069031 (TDC1), AK071599 (T5H), AK059369 (SNAT1), AK068156 (SNAT2), AK064768 (COMT), and Os03g13170 (UBQ5). 


\subsection{Decreased Leaf Angle in the CRY1b RNAi Rice Seedlings}

Blue light promotes leaf bending by upregulating brassinosteroid (BR) biosynthesis genes in rice [40]. Similarly, the overexpression of CRY genes increases the leaf angle in rice, implying a positive relationship between CRY and leaf angle [36]. Additionally, melatonin is positively associated with the leaf angle in rice by regulating BR levels [29]. To investigate the role of $C R Y 1 b$ in determining leaf angle and BR-related gene expression, lamina angles of the second leaves of 10-day-old seedlings grown in soil pots were measured. As shown in Figure 5, the CRY1b RNAi lines had smaller leaf angles than the wild type. To examine the possible contribution of BR-related genes to the decreased leaf angles in the $C R Y 1 b$ RNAi lines, we quantified the expression of various BR-related genes. DWARF, DWARF4, CPD (CONSTITUTIVE PHOTOMORPHOGENIC DWARF), and DET2 (DEETIOLATED2) are BR biosynthesis genes. DWARF converts 6-deoxo-catasterone into catasterone via a $\mathrm{C} 6$ oxidation reaction, whereas DWARF4 converts 6-oxo-campestanol into cathasterone via $\mathrm{C} 22$ hydroxylation. $C P D$ and DET2 encode $\mathrm{C} 3$ oxidase and 5-reductase, respectively [40]. BR-responsive genes include BZR1 (BRASSINAZOLE RESISTANT1; a BR receptor), TXR3 (XYLOGLUCAN ENDOTRANSGLYCOSYLASE RELATED), and BRI1 (BRASSINOSTEROID-INSENSITIVE 1; a transcription factor for BR biosynthesis). TXR3 is a BR-inducible gene encoding a cell wall-loosening enzyme. All BR biosynthesis genes except for DWARF4 were downregulated in the CRY1b RNAi lines compared to the wild type, suggestive of reduced BR synthesis. Our data implicate that $C R Y$ suppression leads to BR suppression in rice. Intriguingly, the decrease in melatonin caused by the suppression of SNAT2 led to a decrease in BR via the suppression of DWARF4 [29]. Collectively, we attribute the BR decrease in the CRY1b RNAi lines mainly to the downregulation of CRY, rather than a decrease in melatonin caused by the suppression of $C R Y 1 b$. The expression of $B Z R 1$ also decreased in the $C R Y 1 b$ RNAi lines relative to the wild type, indicating that $B R$ levels decreased in the $C R Y 1 b$ RNAi lines. Contrary to the results observed for BR biosynthesis genes, BR-responsive genes such as TXR3 and BRI1 were significantly upregulated in the $C R Y 1 \mathrm{~b}$ RNAi lines relative to the wild type, suggesting that these genes are regulated by feedback from reduced levels of endogenous BR.

a

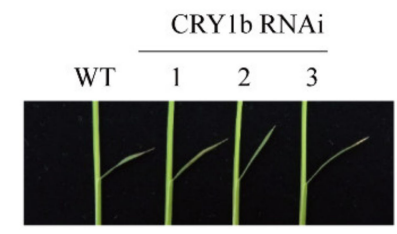

b

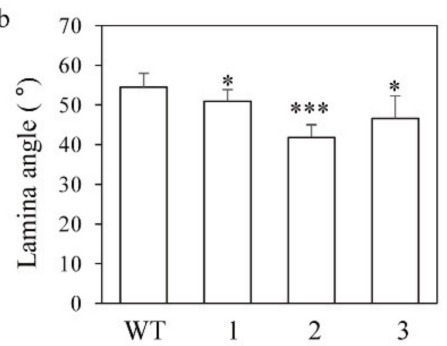

$\mathrm{c}$

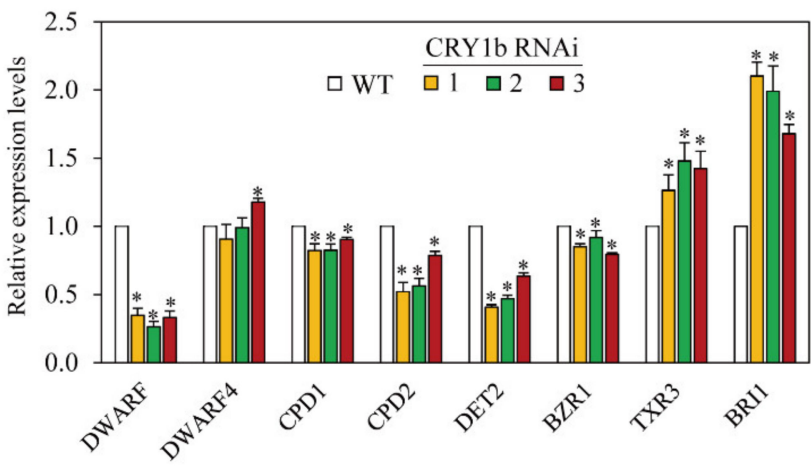

Figure 5. Lamina joint angles and transcript induction profiles of brassinosteroid (BR)-related genes in WT and CRY1b RNAi (1-3) rice plants. (a) Photograph of representative lamina joints in plants grown for 10 days in soil pots. (b) Lamina joint angles in WT and transgenic rice seedlings. (c) Quantitative real-time PCR analysis of the expression of various BR-related genes in WT and CRY1b RNAi plants. GenBank accession numbers are Os03g0602300 (DWARF), Os03g12660 (DWARF4), Os11g0143200 (CPD1), Os12g0139300 (CPD2), Os01g0851600 (DET2), Os07g39220 (BZR1), AP005859 (TXR3), AK101085 (BRI1), and Os03g13170 (UBQ5). Lines 1-3 are RNAi rice plants with downregulated CRY1b genes. ${ }^{*} p<0.05,{ }^{* * *} p<0.001$, Tukey's HSD post-hoc test. 


\subsection{CRY1b RNAi Rice Exhibits Salt Tolerance, Possibly via a Decrease in BR}

Exposure to blue light may increase BR synthesis, possibly via CRY in Arabidopsis and rice [40,41]. In fact, the overexpression of $C R Y 1 a$ conferred hypersensitivity against salt in Arabidopsis, possibly through ABA (abscisic acid) signaling [41]. BR levels have been shown to be negatively associated with abiotic stresses in plants [42-44]. Therefore, a decrease in endogenous BR levels or signaling can lead to abiotic stress tolerance in plants via the $A B A$ and $B R$ signaling pathways $[29,41,44]$. To test whether the CRY1b RNAi lines showing the reduced expression of BR-biosynthetic genes than the wild type confer abiotic tolerance or not, the $C R Y 1 b$ RNAi lines were challenged with salt, and their responses were monitored. As shown in Figure 6, CRY1b RNAi rice exhibited a salt-tolerant phenotype, reflected by reduced production of malondialdehyde (MDA) compared to the wild type. Our data strongly suggest that $C R Y 1 b$ RNAi rice produces less BR than the wild type, which accounts for the enhanced salt tolerance.
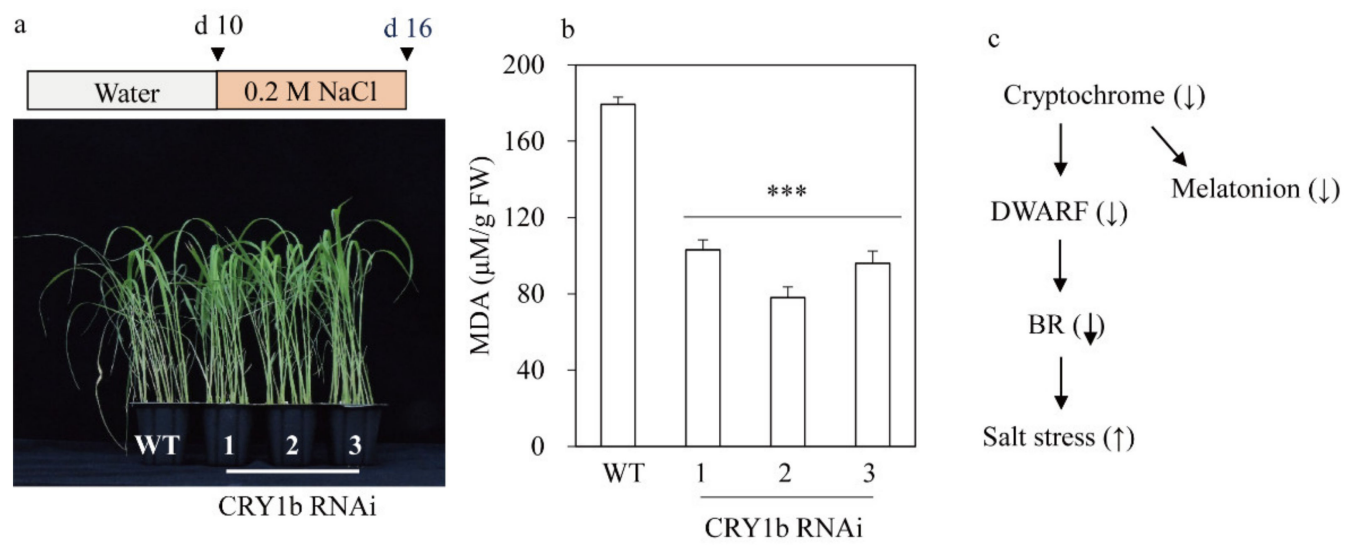

Figure 6. Effects of salt treatment on $C R Y 1 b$ RNAi rice plants. (a) Photograph of representative phenotypes after salt treatment. (b) Malondialdehyde (MDA) levels in WT and transgenic rice plants. (c) Proposed model of CRY-mediated salt tolerance. Values are presented as the means \pm SDs of three independent experiments. FW, fresh weight; $d, d a y .{ }^{* * *} p<$ 0.001, Tukey's HSD post-hoc test.

\section{Materials and Methods}

\subsection{Plant Growth Conditions}

Rice (Oryza sativa cv. Dongjin) seeds were sterilized and grown in soil or half-strength Murashige and Skoog (MS) under cool daylight fluorescent lamps $\left(60 \mu \mathrm{mol} \mathrm{m} \mathrm{m}^{-2} \mathrm{~s}^{-1}\right)$ (Philips, Amsterdam, Netherlands) in a 14-h light/10-h dark photoperiod or blue light $\left(15 \mu \mathrm{mol} \mathrm{m}{ }^{-2} \mathrm{~s}^{-1}\right)$ (STECH LED, Gyeonggi-do, Korea) at $28^{\circ} \mathrm{C} / 24^{\circ} \mathrm{C}$ (day/night). The angles of the lamina joint were measured in the second leaf of $10 \mathrm{~d}$-old rice seedlings grown in soil. For tolerance assay in response to salt stress, 10-d old seedlings were exposed to $200 \mathrm{mM} \mathrm{NaCl}$ for 6 days.

\subsection{Generation of CRY1b Suppression Transgenic Rice by RNA Interference (RNAi)}

The pTCK303 binary vector was used to suppress rice $C R Y 1 b$ gene expression as previously described [45]. Briefly, a C-terminal $288 \mathrm{bp} C R Y 1 b$ cDNA fragment was amplified by PCR using the following primer set: $C R Y 1 b-F 5^{\prime}$-ACT AGT GAA AAT TTCCGTACCACT$3^{\prime}$ (SpeI site underlined) and CRYIb-R $5^{\prime}$-GAG CTC CTG GGA TAA TTG ACT CCA- $3^{\prime}$ (SacI site underlined), with the cDNA templates synthesized from the total RNA from rice seedlings. The $C R Y 1 b$ PCR product was first subcloned into the T\&A cloning vector (T\&A:CRY1b; RBC Bioscience, New Taipei City, Taiwan) for further cloning experiments. From the T\&A:CRY1b plasmid, the antisense CRY1b insert was digested by SacI and SpeI, whereas the sense $C R Y 1 b$ insert was digested by $K p n I$ and BamHI in the T\&A:CRY1b vector. The antisense $C R Y 1 b$ fragment was first ligated into the pTCK303 vector. Thereafter, 
the sense fragment of the CRY1b insert was sequentially ligated into the pTCK303 vector plasmid harboring the corresponding $C R Y 1 b$ antisense fragment (Figure 1a). The resulting pTCK303:CRY1b RNAi binary vector was transformed into A. tumefaciens LBA4404, and into rice (Oryza sativa cv. Dongjin), as previously described [46,47]. In brief, in order to generate transgenic rice plants, scutellum-derived calli from rice $(O$. sativa $\mathrm{cv}$. Dongjin) were co-cultured with Agrobacterium harboring the pTCK303:CRY1b binary vector for 3 days, during which T (transfer)-DNA is incorporated into the rice genome. Thereafter, rice calli were screened on N6 selection medium containing $2 \mathrm{mg} / \mathrm{L}$ 2,4-D and $50 \mathrm{mg} / \mathrm{L}$ hygromycin for 30 days in the dark to generate transgenic calli, and transferred to regeneration media containing $3 \mathrm{mg} / \mathrm{L}$ BAP (6-benzylaminopurine), $1 \mathrm{mg} / \mathrm{L}$ NAA (1-naphthalene acetic acid), and $50 \mathrm{mg} / \mathrm{L}$ hygromycin for shoot and root development. The resulting rice seedlings were grown in a paddy field for obtaining T1 seeds.

\subsection{Cadmium Treatment}

Eight-day old seedlings were incubated in water containing $0.5 \mathrm{mM} \mathrm{CdCl}_{2}$ (SigmaAldrich, St. Louis, MO) under cool daylight fluorescent lamps $\left(60 \mu \mathrm{mol} \mathrm{m}{ }^{-2} \mathrm{~s}^{-1}\right)$ (Philips, Amsterdam, The Netherlands) for 3 days at $28^{\circ} \mathrm{C}$. The leaves and stems were harvested for further analyses.

\subsection{Quantitative Real-Time Polymerase Chain Reaction (qRT-PCR) Analysis}

Total RNA of rice plants was isolated using a NucleoSpin RNA Plant Kit (MachereyNagel, Düren, Germany). First-strand cDNA was synthesized from $2 \mu \mathrm{g}$ of total RNA using MG MMLV Reverse Transcriptase (MGmed, Inc., Seoul, Korea) and an oligo dT 18 primer at $42{ }^{\circ} \mathrm{C}$ for $1 \mathrm{~h}$. qRT-PCR was performed in a Mic qPCR Cycler system (Biomolecular Systems, Queensland, VIC, Australia) with specific primers and the Luna Universal qPCR Master Mix (New England Biolabs, Ipswich, MA, USA), as described previously. The expression of genes was analyzed using Mic's RQ software (Biomolecular Systems) and normalized to ACT1. Semi-quantitative RT-PCR was performed as described previously [2].

\subsection{Quantification of Serotonin, N-acetylserotonin, and Melatonin}

Frozen samples $(0.1 \mathrm{~g})$ were pulverized to a powder in liquid nitrogen using the TissueLyser II (Qiagen, Tokyo, Japan). For serotonin and $N$-acetylserotonin, rice samples were extracted with $1 \mathrm{~mL}$ of methanol for $1 \mathrm{~h}$ at room temperature. The extracts were centrifuged for $10 \mathrm{~min}$ at $12,000 \times g$, and the supernatants $(20 \mu \mathrm{L})$ were subjected to high performance liquid chromatography (HPLC) using a fluorescence detector system (Waters, Milford, MA, USA), as described previously [2]. For melatonin measurement, the samples were extracted with $1 \mathrm{~mL}$ of chloroform for $16 \mathrm{~h}$ at $4{ }^{\circ} \mathrm{C}$. The extracts were centrifuged for $10 \mathrm{~min}$ at $12,000 \times g$, and the supernatants $(20 \mu \mathrm{L})$ were completely evaporated and dissolved in $0.1 \mathrm{~mL}$ of $40 \%$ methanol, and $20-\mu \mathrm{L}$ aliquots were subjected to HPLC using a fluorescence detector system (Waters, Milford, MA, USA), as described previously [2]. All measurements were performed in triplicate.

\subsection{Malondialdehyde Measurement}

The rice samples (50 mg) were ground and extracted with $1.5 \mathrm{~mL}$ of reaction buffer (containing $0.5 \%$ thiobarbituric acid (TBA) and 20\% trichloroacetic acid (TCA)). The extracts were centrifuged for $15 \mathrm{~min}$ at $12,000 \times g$, and the resulting supernatants were collected for measurement. The supernatant was boiled for $25 \mathrm{~min}$ at $95^{\circ} \mathrm{C}$, and placed for $5 \mathrm{~min}$ in ice. MDA content was determined at 440,532, and $600 \mathrm{~nm}$ wavelengths using a spectrophotometer (OPIZEN POP-BIO). MDA was quantified using a molar extinction coefficient of $156 / \mathrm{nM} / \mathrm{cm}$.

\subsection{List of Primers for $q R T-P C R$}

The following primers were utilized for qRT-PCR and semiquantitative RT-PCR. CRY1a (forward 5'-AGA TGG AAG TTG ACC GAG-3'; reverse 5'-AGG CTG GAA GAG 
CAC CTG CG-3'), CRY1b (forward 5'-AGA TGG AAG TTG ACC GAG -3'; reverse 5'-AGG CTC AAA ATT CAC ACG GGT-3'), CRY2 (forward $5^{\prime}$-ACG AGC TCT GTA GCA AAC TCA-3'; reverse $5^{\prime}$ - TTT TCG TTG TCT TGA AAT GCT-3'), TDC1 (forward $5^{\prime}$-GCG AGG GTG AAA CCT TCC A-3'; reverse $5^{\prime}$-GCG AGC CGG TGG AGT CC-3'), T5H (forward $5^{\prime}$-CCT CGT CCT GGA CAT GTT CGT C-3'; reverse $5^{\prime}$-ATG GCG AAC GTG TTG ATG AAC AC-3'), SNAT1 (forward 5'-CAG TAG AGC CAC CAT CAG CA-3'; reverse $5^{\prime}$-ATC CCA CCT TGT CGC ATA AA-3'), SNAT2 (forward 5'-GTC TGG GAC GTG GTC GTG-3'; reverse $5^{\prime}$-GTT GCC TTG AGC GGT AGA AG-3'), COMT (forward 5'-CCT GCT CGC CTC CTA CAA-3'; reverse 5' - ATG CCC TCG TTG AAG ACG-3'), DWARF (forward 5'-GGA GAA GAA CAT GGA ATC AC - $3^{\prime}$; reverse $5^{\prime}$-GTA ATC TTG AAC GCG GAT ATG - $3^{\prime}$ ), DWARF4 (forward 5'-GTG CTG CCA TTC TCG GAG TAA TAG-3'; reverse 5'-CTC AGC AAG AGG TCC AGG ATT TGC-3'), CPD1 (forward $5^{\prime}$-CGA CGG CCT TCT TCT CCA T-3'; reverse 5'-AGG GCC TGG CCG TAG GT-3'), CPD2 (forward 5'-CAC CAC ACG AAC TCT CAA AGG A-3'; reverse $5^{\prime}$-GCA AAA CAA TCT AAC GTC AGC AA-3'), DET2 (forward 5'-CCT CTG TTA TTG CTG ATG GAT ACG-3'; reverse $5^{\prime}$-ATG CCA ACA GTA TGA ATC AAA AGC-3'), BRI1 (forward 5'-CAG CTT GGA GGA TGT GTT GCGGA-3'; reverse $5^{\prime}$-TCT TCG AGT CGA CCG TCG AC-3'), XTR3 (forward 5'-ATC GGA GCA GCT AGC TAG AG-3'; reverse 5'-GTA GAA GGC AAC GAC GAC GC-3'), BZR1 (forward 5'-ATG ACG GCC ATT ATT GCC GAG CA-3'; reverse $5^{\prime}$-TCG CCC AAA TCG CAG CAT-3'), ACT1 (forward 5'-TGC TAT GTA CGT CGC CAT CCA G-3'; reverse 5'-AAT GAG TAA CCA CGC TCC GTC AA- $\left.3^{\prime}\right)$.

\subsection{Statistical Analysis}

The data were analyzed using analysis of variance using IBM SPSS Statistics 23 software (IBM Corp. Armonk, NY, USA). Means with asterisks indicate significantly different values at $p<0.05\left(^{*}\right)$, or $0.001(* *)$ according to least significance difference (LSD) test. All data are presented as mean \pm standard deviation.

\section{Conclusions}

Unlike melatonin production in animals, which peaks in the dark, melatonin biosynthesis in plants requires light. No melatonin was induced during dark incubation when rice plants were challenged with cadmium, whereas large amounts of melatonin were induced when plants were incubated in light [2]. From the results of more detailed experiments, we found that light quality played a role in light-induced melatonin biosynthesis, and the combination of red and blue light led to maximum melatonin production, followed by red light alone and blue light alone. In comparison, melatonin is not induced in rice with cadmium treatment upon exposure to far-red light and the dark. The role of light quality in melatonin synthesis was confirmed genetically, with rice phytochrome (red and far-red photoreceptors) mutants synthesizing less melatonin than the wild type, which implies that melatonin synthesis is light-dependent in plants [33]. Here, we tested whether the blue-light photoreceptor (CRY) is also involved in melatonin biosynthesis. We generated $C R Y 1 b$ RNAi rice and challenged rice plants with cadmium to induce melatonin. As expected, reduced melatonin synthesis was observed in the $C R Y 1 b$ RNAi lines compared to the wild type, providing further evidence for light-dependent melatonin biosynthesis in plants.

Author Contributions: Conceptualization, K.B.; formal analysis, O.J.H.; investigation, O.J.H.; data curation, O.J.H.; writing—original draft preparation, K.B.; writing—-review and editing, K.B.; project administration, K.B.; funding acquisition, K.B. All authors have read and agreed to the published version of the manuscript.

Funding: This research was supported from the BioGreen 21-linked Innovative Agricultural Research and Technology Development Program (Project No. PJ01570301), funded by the Rural Development Administration, Republic of Korea.

Institutional Review Board Statement: Not applicable. 
Informed Consent Statement: Not applicable.

Data Availability Statement: The data presented in this study are available on request from the corresponding author.

Conflicts of Interest: The authors declare no conflict of interest.

Sample Availability: Not applicable.

\section{References}

1. Kolář, J.; Macháćková, I.; Eder, J.; Prinsen, E.; Van Dongen, W.; Van Onckelen, H.A.; Illnerova, H. Melatonin: Occurrence and daily rhythm in Chenopodium rubrum. Phytochemistry 1997, 44, 1407-1413. [CrossRef]

2. Lee, K.; Choi, G.H.; Back, K. Cadmium-induced melatonin synthesis in rice requires light, hydrogen peroxide, and nitric oxide: Key regulatory roles for tryptophan decarboxylase and caffeic acid O-methyltransferase. J. Pineal Res. 2017, 63, e12441. [CrossRef] [PubMed]

3. Zhao, D.; Yu, Y.; Shen, Y.; Liu, Q.; Zhao, Z.; Sharma, R.; Reiter, R.J. Melatonin synthesis and function: Evolutionary history in animals and plants. Front. Endocrinol. 2019, 10, 249. [CrossRef]

4. Zimmerman, S.; Reiter, R.J. Melatonin and the optics of the human body. Melatonin Res. 2019, 2, 138-160. [CrossRef]

5. Hardeland, R. Melatonin in the evolution of plants and other phototrophs. Melatonin Res. 2019, 2, 10-36. [CrossRef]

6. Tan, D.X.; Reiter, R.J. Mitochondria: The birth place, battle ground and site of melatonin metabolism in cells. Melatonin Res. 2019, 2, 44-66. [CrossRef]

7. Tan, D.X.; Reiter, R.J. An evolutionary view of melatonin synthesis and metabolism related to its biological functions in plant. J. Exp. Bot. 2020, 71, 4677-4689. [CrossRef] [PubMed]

8. Back, K. Melatonin metabolism, signaling and possible roles in plants. Plant J. 2021, 105, 376-391. [CrossRef] [PubMed]

9. Tan, D.X.; Hardeland, R. Targeting host defense system and rescuing compromised mitochondria to increase tolerance against pathogens by melatonin may impact outcome of deadly virus infection pertinent to COVID-19. Molecules 2020, 25, 4410. [CrossRef]

10. Wei, J.; Li, D.X.; Zhang, J.R.; Shan, C.; Rengel, Z.; Song, Z.B.; Chen, Q. Phytomelatonin receptor PMTR1-mediated signaling regulates stomatal closure in Arabidopsis thaliana. J. Pineal Res. 2018, 65, e12500. [CrossRef]

11. Lee, H.Y.; Back, K. The phytomelatonin receptor (PMRT1) Arabidopsis Cand2 is not a bona fide G protein-coupled melatonin receptor. Melatonin Res. 2020, 3, 177-186. [CrossRef]

12. Khan, A.; Numan, M.; Khan, A.L.; Lee, I.J.; Imran, M.; Asaf, S.; Al-Harrasi, A. Melatonin: Awakening the defense mechanisms during plant oxidative stress. Plants 2020, 9, 407. [CrossRef]

13. Moustafa-Farag, M.; Almoneafy, A.; Mahmoud, A.; Elkelish, A.; Arnao, M.B.; Li, L.; Ai, S. Melatonin and its protective role against biotic stress impacts on plants. Biomolecules 2020, 10, 54. [CrossRef]

14. Arnao, M.B.; Hernández-Ruiz, J. Melatonin in flowering, fruit set and fruit ripening. Plant Reprod. 2020, 33, 77-87. [CrossRef] [PubMed]

15. Ozgur, R.; Uzilday, B.; Turkan, I.; Sekmen, A.H. The effects of melatonin on transcriptional profile of unfolded protein response genes under endoplasmic reticulum stress in Arabidopsis thaliana. Plant Mol. Biol. Rep. 2017, 35, 188-202. [CrossRef]

16. Lee, H.Y.; Back, K. Melatonin plays a pivotal role in conferring tolerance against endoplasmic reticulum stress via mitogenactivated protein kinases and bZIP60 in Arabidopsis thaliana. Melatonin Res. 2018, 1, 93-107. [CrossRef]

17. Cen, H.; Wang, T.; Liu, H.; Tian, D.; Zhang, Y. Melatonin application improves salt tolerance of alfalfa (Medicago sativa L.) by enhancing antioxidant capacity. Plants 2020, 9, 220. [CrossRef] [PubMed]

18. Liu, J.; Shabala, S.; Zhang, J.; Ma, G.; Chen, D.; Shabala, L.; Zeng, F.; Chen, Z.H.; Zhou, M.; Venkataraman, G.; et al. Melatonin improves rice salinity stress tolerance by NADPH oxidase-dependent control of the plasma membrane $\mathrm{K}^{+}$transporters and $\mathrm{K}^{+}$ homeostasis. Plant Cell Environ. 2020, 43, 2591-2605. [CrossRef]

19. Chen, X.; Laborda, P.; Liu, F. Exogenous melatonin enhances rice plant resistance against Xanthomonas oryzae pv. oryzae. Plant Dis. 2020, 104, 1701-1708. [CrossRef]

20. Madigan, A.P.; Harris, C.; Bedon, F.; Franks, A.E.; Plummer, K.M. High doses of melatonin confer abiotic stress tolerance to phytopathogenic fungi grown in vitro. Melatonin Res. 2020, 3, 187-193. [CrossRef]

21. Buttar, Z.A.; Wu, S.N.; Arnao, M.B.; Wang, C.; Ullah, I.; Wang, C. Melatonin suppressed the heat stress-induced damage in wheat seedlings by modulating the antioxidant machinery. Plants 2020, 9, 809. [CrossRef]

22. Wang, X.; Zhang, H.; Xie, Q.; Liu, Y.; Lv, H.; Bai, R.; Ma, R.; Li, X.; Zhang, X.; Guo, Y.D.; et al. SISNAT interacts with HSP40, a molecular chaperone, to regulate melatonin biosynthesis and promote thermotolerance in tomato. Plant Cell Physiol. 2020, 61, 909-921. [CrossRef] [PubMed]

23. Bychkov, I.; Kudryakova, N.; Andreeva, A.; Pojidaeva, E.; Kusnetsov, V. Melatonin modifies the expression of the genes for nuclear- and plastid-encoded chloroplast proteins in detached Arabidopsis leaves exposed to photooxidative stress. Plant Physiol. Biochem. 2019, 144, 404-412. [CrossRef]

24. Wang, Y.; Reiter, R.J.; Chan, Z. Phytomelatonin: A universal abiotic stress regulator. J. Exp. Bot. 2018, 69, 963-974. [CrossRef]

25. Gao, S.; Ma, W.; Lyu, X.; Cao, X.; Yao, Y. Melatonin may increase disease resistance and flavonoid biosynthesis through effects on DNA methylation and gene expression in grape berries. BMC Plant Biol. 2020, 20, 231. [CrossRef] 
26. Li, D.; Guo, Y.; Zhang, D.; He, S.; Gong, J.; Ma, H.; Gao, X.; Wang, Z.; Jiang, L.; Dun, X.; et al. Melatonin represses oil and anthocyanin accumulation in seeds. Plant Physiol. 2020, 183, 898-914. [CrossRef]

27. Xiao, S.; Liu, L.; Wang, H.; Li, D.; Bai, Z.; Zhang, Y.; Sun, H.; Zhang, K.; Li, C. Exogenous melatonin accelerates seed germination in cotton (Gossypium hirsutum L.). PLoS ONE 2019, 14, e0216575. [CrossRef] [PubMed]

28. Hwang, O.J.; Back, K. Simultaneous suppression of two distinct serotonin $N$-acetyltransferase isogenes by RNA interference leads to severe decreases in melatonin and accelerated seed deterioration in rice. Biomolecules 2020, 10, 141. [CrossRef] [PubMed]

29. Hwang, O.J.; Back, K. Melatonin deficiency confers tolerance to multiple abiotic stresses in rice via decreased brassinosteroid levels. Int. J. Mol. Sci. 2019, 20, 5173. [CrossRef] [PubMed]

30. Liu, S.; Huang, H.; Huber, D.J.; Pan, Y.; Shi, X.; Zhang, Z. Delay of ripening and softening in "Guifei" mango fruit by postharvest application of melatonin. Postharvest Biol. Technol. 2020, 163, 111136. [CrossRef]

31. Xia, H.; Shen, Y.; Shen, T.; Wang, X.; Zhang, X.; Hu, P.; Liang, D.; Lin, L.; Deng, H.; Wang, J.; et al. Melatonin accumulation in sweet cherry and its influence on fruit quality and antioxidant properties. Molecules 2020, 25, 75. [CrossRef] [PubMed]

32. Arnao, M.B.; Hernández-Ruiz, J. Melatonin: A new plant hormone and/or a plant master regulator? Trends Plant Sci. 2019, 24, 38-48. [CrossRef]

33. Hwang, O.J.; Kang, K.; Back, K. Effects of light quality and phytochrome from on melatonin biosynthesis in rice. Biomolecules 2020, 10, 523. [CrossRef] [PubMed]

34. Buchanan, B.B.; Gruissem, W.; Jones, R.L. Biochemistry and Molecular Biology of Plants; American Society of Plant Physiologists: Rockville, MD, USA, 2000; pp. 568-628.

35. Forsyth, J.A.; Erland, L.A.E.; Shipley, P.R.; Murch, S.J. Plant perception of light: The role of indoleamines in Scutellaria species. Melatonin Res. 2020, 3, 161-176. [CrossRef]

36. Hirose, F.; Shinomura, T.; Tanabata, T.; Shimada, H.; Takano, M. Involvement of rice cryptochromes in de-etiolation responses and flowering. Plant Cell Physiol. 2006, 47, 915-925. [CrossRef]

37. Zhang, Y.C.; Gong, S.F.; Li, Q.H.; Sang, L.; Yang, H.Q. Functional and signaling mechanism analysis of rice CRYTOCHROME 1. Plant J. 2006, 46, 971-983. [CrossRef] [PubMed]

38. Biswas, K.K.; Neumann, R.; Haga, K.; Yatoh, O.; Lino, M. Photomorphogenesis of rice seedlings: A mutant impaired in phytochrome-mediated inhibition of coleoptile growth. Plant Cell Physiol. 2003, 44, 242-254. [CrossRef] [PubMed]

39. Byeon, Y.; Choi, G.H.; Lee, H.Y.; Back, K. Melatonin biosynthesis requires N-acetylserotonin methyltransferase activity of caffeic acid O-methyltransferase in rice. J. Exp. Bot. 2015, 66, 6917-6925. [CrossRef] [PubMed]

40. Asahina, M.; Tamaki, Y.; Sakamoto, T.; Shibata, K.; Nomura, T.; Yokota, T. Blue light-promoted rice leaf bending and unrolling are due to up-regulated brassinosteroid biosynthesis genes accompanied by accumulation of catasterone. Phytochemistry 2014, 104, 21-29. [CrossRef]

41. Zhou, T.; Meng, L.; Ma, Y.; Liu, Q.; Zhang, Y.; Yang, Z.; Yang, D.; Bian, M. Overexpression of sweet sorghum crytochrome 1a confers hypersensitivity to blue light, abscisic acid and salinity in Arabidopsis. Plant Cell Rep. 2018, 37, 251-264. [CrossRef]

42. Kim, S.Y.; Kim, B.H.; Lim, C.J.; Lim, C.O.; Nam, K.H. Constitutive activation of stress-inducible genes in a brassinosteroid-insensitive 1 (bri1) mutant results in higher tolerance to cold. Physiol. Plant. 2010, 138, 191-204. [CrossRef] [PubMed]

43. Chung, Y.; Kwon, S.I.; Choe, S. Antagonistic regulation of Arabidopsis growth by brassinosteroids and abiotic stresses. Mol. Cells 2014, 37, 795-803. [CrossRef]

44. Northey, J.G.B.; Liang, S.; Jamshed, M.; Deb, S.; Foo, E.; Reid, J.B.; McCourt, P.; Samuel, M.A. Farnesylation mediates brassinosteroid biosynthesis to regulate abscisic acid responses. Nat. Plants 2016, 2, 16114. [CrossRef]

45. Wang, Z.; Chen, C.; Xu, Y.; Jiang, R.; Han, Y.; Xu, Z.; Chong, K. A practical vector for efficient knockdown of gene expression in rice (Oryza sativa L.). Plant Mol. Biol. Rep. 2004, 22, 409-417. [CrossRef]

46. Choi, G.H.; Back, K. Suppression of melatonin 2-hydroxylase increases melatonin production leading to the enhanced abiotic stress tolerance against cadmium, senescence, salt, and tunicamycin in rice plants. Biomolecules 2019, 9, 589. [CrossRef] [PubMed]

47. Lee, K.; Hwang, O.J.; Back, K. Rice $\mathrm{N}$-acetylserotonin deacetylase regulates melatonin levels in transgenic rice. Melatonin Res. 2020, 3, 32-42. [CrossRef] 